\title{
Coulisses
}

Revue de théâtre

14 | Printemps 1996

Varia

\section{Didon et Enée}

Opéra en un prologue et trois actes de Henry Purcell, livret de Nahum Tate

\section{Clément François}

\section{(2) OpenEdition \\ 12 Journals}

Édition électronique

URL : http://journals.openedition.org/coulisses/4887

DOI : $10.4000 /$ coulisses.4887

ISSN : 2546-9460

Éditeur

Presses universitaires de Franche-Comté

\section{Édition imprimée}

Date de publication : 1 mai 1996

Pagination : 83

ISSN : 1150-594X

\section{Référence électronique}

Clément François, «Didon et Enée », Coulisses [En ligne], 14 | Printemps 1996, mis en ligne le 20 mars

2019, consulté le 24 septembre 2020. URL : http://journals.openedition.org/coulisses/4887 ; DOI :

https://doi.org/10.4000/coulisses.4887

Ce document a été généré automatiquement le 24 septembre 2020.

Coulisses 


\title{
Didon et Enée
}

\author{
Opéra en un prologue et trois actes de Henry Purcell, livret de Nahum \\ Tate
}

\section{Clément François}

Présenté le mardi 23 avril à l'Opéra Théâtre de Besançon dans le cadre « scène ouverte sur la ville»

Entretien avec Jean-Luc Clairet, metteur en scène

Propos recueillis par Clément François

c.F. : Vous venez de mettre en scène Didon et Enée de Purcell à l'Opéra Théâtre mais en fait vous êtes instituteur, non?

J.L.C.: En effet, depuis de nombreuses années que je fais des spectacles avec des élèves. Il se trouve que Claire-Marie Mille, chef d'orchestre de la production a vu certains d'entre eux. Elle avait besoin à l'époque d'un assistant pour Charlotte Nessi pour une opération autour du bicentenaire de la Révolution Française avec une centaine d'enfants.

Deux ans après, elle m'a confié la mise en scène d'un spectacle sur des textes de Prévert et une musique de Kosma au Kursaal à Besançon. Les responsables de Muse et Danse, groupe de danse ancienne qui co-produit le spectacle, étaient aussi venus voir La Cantatrice chauve monté avec mes élèves de l'école de Roset-Fluans et repris à l'Espace Planoise ...et ils avaient beaucoup aimé !

C.F. : Pourquoi avez-vous choisi de monter Didon et Enée?

J.L.C. : Muse et Danse m'a proposé pendant l'été 94 de monter Les Fêtes Vénitiennes de Campra. Après audition de l'œuvre, je n'étais pas vraiment séduit par la musique et l'intrigue : ce n'était qu'un divertissement avec une vague intrigue amoureuse.

J'ai pensé à une autre œuvre, Didon et Enée de Purcell qui est un opéra où les passages dansés ont beaucoup d'importance, où il y a une belle trame dramatique, et du divertissement... J'ai toujours été passionné par cette œuvre surtout par les versions qui incluent les passages souvent coupés comme les danses à la guitare et aussi le prologue qui n'est pratiquement jamais donné et qui pourtant est très beau. 
c.F. : Choisir de monter un opéra, avec des danseurs, des chanteurs solistes, un chœur... c'est toute une aventure!

J.L.C. : 21 choristes, 7 solistes, 10 danseurs, 11 musiciens, 1 figurant... toute l'équipe technique du théâtre, en effet, c'est une véritable aventure!

Le travail avec les professionnels et les amateurs s'est très bien passé au-delà même de mes espérances!

$\mathrm{Au}$ début j'avais un peu peur que les solistes professionnels soient un peu rétifs à certains passages de la mise en scène.

C.F. : Pourquoi ?

J.L.C.: Dès le début, je savais que techniquement ce serait plus lourd qu'on ne l'imaginait. Les machinistes par exemple, avaient à faire bouger le décor toutes les trois minutes environ; les solistes avaient des contraintes inhabituelles puisque certains devaient rester plusieurs minutes couchés sous un drap immense avant de réapparaître dans la scène suivante... Cela pouvait les déstabiliser avant de chanter mais ces moments avaient lieu dans des scènes où leur partie était plus légère, donc cela pouvait être jouable! Pour le personnage de Bélinda, par exemple, je n'étais pas sûr que Jill Feldman allait accepter de jouer cette carte d'une Bélinda plutôt négative, alors que d'habitude c'est un personnage d'une grande gentillesse à la limite de la fadeur! Mais ils m'ont fait confiance et ils se sont même déclarés complètement convaincus par les personnages tels qu'ils devaient les interpréter.

C.F. : Les danseurs avaient aussi à exécuter des danses baroques en costumes de plage...

J.L.C. : Je savais dès le début que cela allait être très troublant, la gestuelle baroque semble être quelque chose de très, très ancien mais la transposer de nos jours pouvait être délectable et avoir beaucoup d'allure. Ça pouvait être intéressant d'introduire ce geste beau et ancien sur une plage à notre époque.

C.F. : Seriez-vous partant pour une nouvelle aventure?

J.L.C. : La dernière semaine a été tellement grisante qu'elle m'a fait oublier toutes les semaines et mois d'angoisses. Je pensais que les derniers jours allaient être très difficiles avec des soucis et des tas de problèmes à régler. Pourtant, à l'approche du spectacle avec les derniers filages, les lumières, les costumes, l'aventure prenait tout son sens et m'a fait oublier les moments difficiles. 